Research article

Open Access

\title{
Alcohol Dehydrogenases as Tools for the Preparation of Enantiopure Metabolites of Drugs with Methyl Alkyl Ketone Moiety
}

\author{
Elżbieta PęKALA *, Dorota ŻELASZCZYK
}

Department of Technology and Biotechnology of Drugs, Medical College of Jagiellonian University, Medyczna 9, 30-680 Cracow, Poland

* Corresponding author. E-mail: epekala@cm-uj.krakow.pl (E. Pękala)

Sci Pharm. 2009; 77: 9-17

doi:10.3797/scipharm.0901-26

Published: $\quad$ February $17^{\text {th }} 2009$

Accepted: $\quad$ February $17^{\text {th }} 2009$

Received: January $26^{\text {th }} 2009$

This article is available from: http://dx.doi.org/10.3797/scipharm.0901-26

(c) Pękala and Żelaszczyk; licensee Österreichische Apotheker-Verlagsgesellschaft m. b. H., Vienna, Austria.

This is an Open Access article distributed under the terms of the Creative Commons Attribution License (http://creativecommons.org/licenses/by/3.0/), which permits unrestricted use, distribution, and reproduction in any medium, provided the original work is properly cited.

\begin{abstract}
Three dehydrogenases - (R)-alcohol dehydrogenase from L. kefir, (S)-aromatic alcohol dehydrogenase from $T$. sp. and (S)-alcohol dehydrogenase from $T$. brockii - were tested for the preparation of enantiopure hydroxyl metabolites of pentoxifylline (PTX), propentofylline (PPT) and denbufylline (DBF). These metabolites have an important pharmacological significance. The experimental conditions were optimized for biocatalytic reactions. $L K A D H$ produced the chiral secondary alcohols: $(R)$-OHPTX, $(R)$-OHPPT and $(R)$-OHDBF, in an antiPrelog's rule configuration. In contrast, TBADH and SAADH also generated chiral secondary alcohols, but according to Prelog's rule, giving (S)-OHPTX, (S)-OHPPT and (S)-OHDBF respectively. All the ADHs tested were characterized by a high enantioselectivity (ees of 99-100\%), but the yield of bioconversion was only satisfactory for the reactions performed using $L K A D H$, being in the $96-98 \%$ range for PPT and PTX respectively.
\end{abstract}

\section{Keywords}

Alcohol dehydrogenases - Stereoselective bioreduction - Pentoxifylline - Propentofylline • Denbufylline

\section{Introduction}

Enzymes are being used ever more widely in industrial synthetic chemistry as excellent catalysts. Enzymes allow the omission not only of the tedious blocking and deblocking 
steps that are common in enantioselective and regioselective organic synthesis, but also avoid the waste of fossil fuels required for preparing high-temperature and high-pressure consolidations. Thus, from the economic and environmental point of view, enzymes are considered more satisfactory than conventional catalysts.

Chiral alcohols are very useful materials in the specialty chemical and pharmaceutical industries. Enantiomerically pure alcohols are valuable chiral building blocks for industrial fine chemicals. For example, the compounds act as key intermediates in the production of pharmaceuticals, fine chemicals and natural products. Examples of pharmaceuticals with chiral alcohols as intermediates are antihypertensive drugs, calcium and potassium channel blocking drugs, antiarrhythmic agents, $\beta_{3}$-receptor agonists, anticholesterol and antiviral drugs. The interconversion of a ketone to the corresponding chiral alcohol and vice versa represents one of the most common redox-reactions in organic chemistry. Whereas traditional synthetic methods predominantly use toxic metals and expensive complex hydrides, biotransformations offer some significant advantages. Various chiral alcohols can be produced by biocatalysis using two methods: kinetic resolution of the racemic starting material [1,2], or direct synthesis from a prochiral compounds [3-6]. The asymmetric reduction of prochiral carbonyl substrate is one example of direct synthesis. The vast majority of dehydrogenases and reductases used for ketone reduction and alcohol oxidation require nicotinamide cofactors, such as NADH and NADPH.

For the synthesis of chiral alcohols, commercially available alcohol dehydrogenases (ADHs) isolated from yeast (NADH dependent $\mathrm{YADH}$ ), horse liver (NADH dependent $\mathrm{HLADH}$ ) or Thermoanaerobium brockii (NADPH-dependent TBADH) can be used for different substrate structures. Horse-liver ADH can be used for the reduction of a broad range of cyclic ketones and 2- or 3-ketoesters [7], while open-chain methyl and ethyl ketones are the preferred substrates for T. brockii ADH [8]. An NADPH-dependent ADH from Rhodococcus erythropolis (READH) was found that reduces a broad variety of ketones with specific activity, giving $(S)$-alcohols $[9,10]$. Furthermore, an NADPHdependent ADH was found in Lactobacillus that converted similar ketone structures but formed (R)-alcohols [11-13]. Lactobacillus kefiri produces an (R)-ADH (LKADH) that accepts a broad variety of ketone substrates - including acetophenone and derivatives (ring halogenated), aliphatic, open-chain ketones, 2-, 3-ketoesters, and cyclic ketones with a high specific activity. In the majority of cases enzymatic and microbial reductions of the alkyl aryl ketones proceed according to Prelog's rule [14, 15] generating alcohols in the (S)-configuration. The majority of enzymes, such as HLADH, YADH, TBADH and ADH from $R$. erythropolis, follow this rule, while only a few (e.g. LKADH) have been described as possessing enzymes of the opposite specificity, i.e. anti-Prelog's specificity [16].

In this study we present the results of the enantioselective bioreduction of drugs i.e. pentoxifylline (PTX), propentofylline (PPT) and denbufylline (DBF) (Fig. 1) using the commercially available dehydrogenases: $(R)$-alcohol dehydrogenase from $L$. kefir, (S)aromatic alcohol dehydrogenase from $T$. sp. and (S)-alcohol dehydrogenase from $T$. brockii. The drugs tested possess a methyl ketone moiety in their structures which was reduced biocatalytically by alcohol dehydrogenases. The chiral products obtained are important, pharmacologically significant metabolites [17-23]. For example (R)-hydroxy metabolite of PTX ((R)-OHPTX), known as lisofylline, is a drug candidate that has been under investigation for acute respiratory distress syndrome (ADRS), acute lung injury (ALI), septic shock, and mucositis. Moreover, it may prevent neutropenic infections in 
cancer patients receiving high dose chemotherapy [24], and it has also been found to be effective in the prevention and treatment of Type 1 diabetes [25]. In contrast, the enantiomeric antipode of lisofylline ((S)-OHPTX) is considered to be pharmacologically inactive. Studies have shown also, that the racemic mixture and the stereoisomers of OHPPT demonstrates biological activity. Hydroxy metabolites of PPT inhibited $\left[{ }^{3} \mathrm{H}\right]$ nitrobenzylthioinosyne binding in rat brains with a similar affinity to propentofylline, and also inhibited $\left[{ }^{3} \mathrm{H}\right]$ adenosine uptake by transport as effectively as propentofylline. Since inhibition of adenosine transport appears to be important for the neuroprotective effect of PPT, the hydroxy metabolites may also provide neuroprotection [26].

\section{Results and Discussion}

\section{Configuration}

The bioconversion of PTX, PPT and DBF (Fig. 1) was carried out using three commercially-available alcohol dehydrogenases. One of them, $L K A D H$, produced the chiral secondary alcohols, (R)-OHPTX, (R)-OHPPT and $(R)$-OHDBF, through enantioselective bioreduction, giving an anti-Prelog's rule configuration. The two remaining dehydrogenases, TBADH and SAADH, also generated chiral secondary alcohols, but according to Prelog's rule, giving (S)-OHPTX, (S)-OHPPT or (S)-OHDBF, respectively. The product configuration and the enantioselectivity of the enzymatic reduction were determined using chiral HPLC comparison of the reduction product with the reference agents which we had previously obtained [27-29].

\section{Bioreduction conditions}

In all the assays the substrate concentration was kept in the $2.5-4.0 \mathrm{mM}$ range. Bioreductions were performed under different conditions: $\mathrm{pH}$ 7.0-7.5, cofactor concentration 1.25-2.0 mM, cofactor regeneration system: 2-propanol 6-8 \% v/v. The secondary alcohol, 2-propanol, performs a dual role: firstly, it serves to recycle the cofactor, and secondly it improves the solubility of the substrate in the aqueous medium. DBF was poorly soluble in the reaction mixture in comparison to PTX or PPT. Unfortunately, even the 2-propanol used to recycle the NADP did not improve the solubility of DBF. In this case, therefore, it was necessary to use a cosolvent, DMSO (2-2.5\%), to ensure an appropriate solubility of DBF in the reaction medium. The results are summarized in table 1. All the ADHs tested displayed enantioselective activity (ee 99$100 \%$ ), but only the yield of bioconversion of the reactions performed using LKADH was satisfactory, in the 96-98\% range. For TBADH and SAADH the yield was very low and reached a level of only $5-10 \%$.

Unsatisfactory results were observed for bioreductions using SAADH. This enzyme was characterized by a high enantioselectivity for PTX and PPT but a very low yield of bioconversion, reaching at maximum level of $5 \%$. SAADH was inactive in regard to DBF. Not even a trace was obtained of a DBF bioconversion product. 

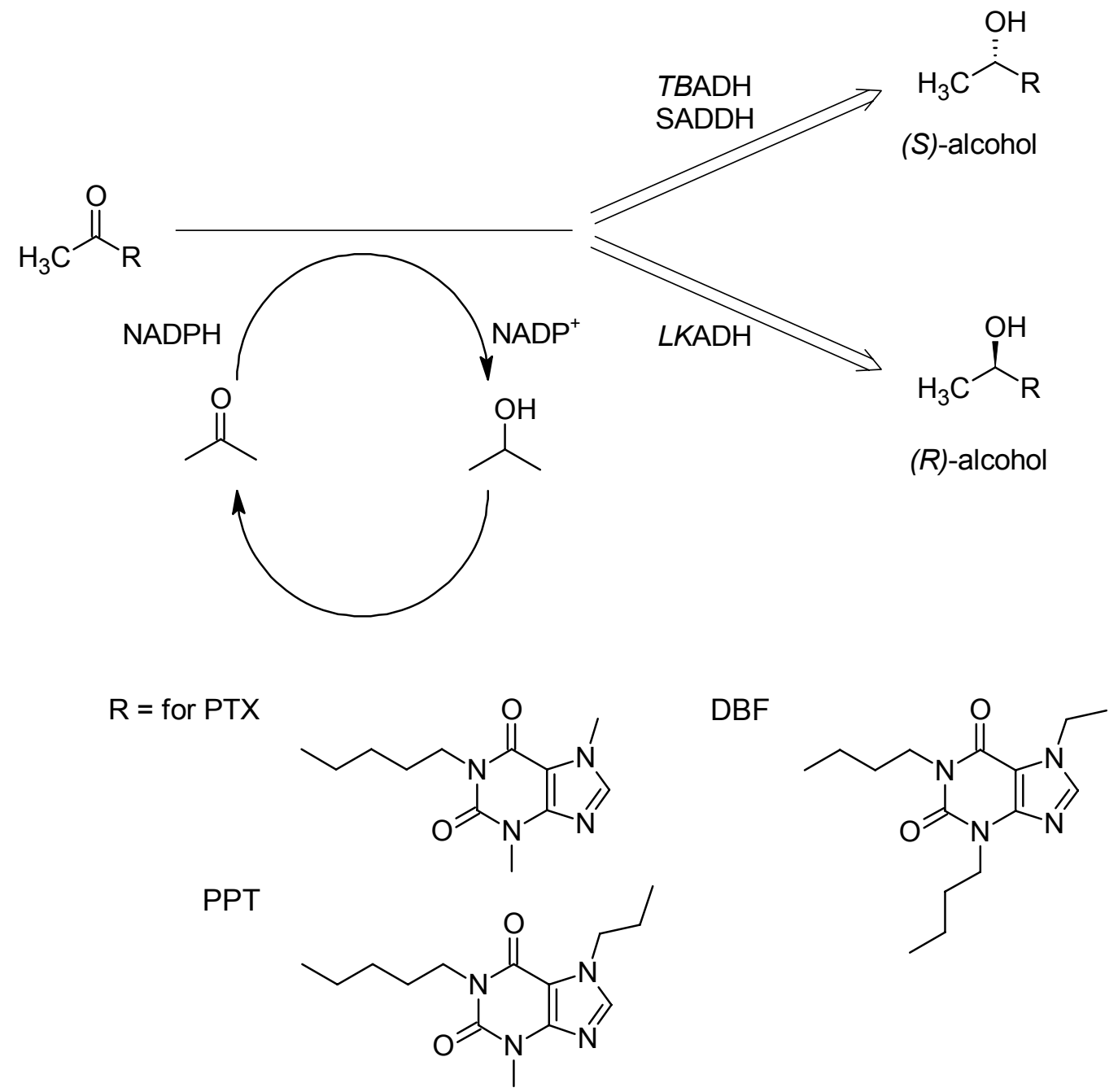

Fig. 1. The bioreduction pathway of xanthine with methyl alkyl ketone moiety.

Tab. 1. Bioreduction of PTX, PPT and DBF with different ADHs.

\begin{tabular}{ccccc}
\hline ADHs & Substrate & Product & HPLC yield (\%) & ee (\%) \\
\hline LKADH & PTX & R-OHPTX & 96 & $>99$ \\
& PPT & R-OHPPT & 98 & $>99$ \\
& DBF & R-OHDBF & 11 & $>99.9$ \\
TBADH & PTX & S-OHPTX & 10 & 100 \\
& PPT & S-OHPPT & 9 & 100 \\
& DBF & S-OHDBF & 8 & $>99.9$ \\
SAADH & PTX & S-OHPTX & 5 & $>99.9$ \\
& PPT & S-OHPPT & 5 & $>99.9$ \\
& DBF & - & 0 & -
\end{tabular}

The results presented in this paper show that commercially available dehydrogenases can be tools for the preparation of enantiopure hydroxyl metabolites of PTX, PPT and DBF. The highest activity with regard to the drugs tested was shown by LKADH. The tested 
agents were converted by this enzyme to appropriate $(R)$-hydroxy metabolites with a high yield. The procedure using $\angle K A D H$ can be an alternative to the whole cell methodology using Lactobacillus kefiri, which we previously described (Table 2) $[11,28]$. Using whole cells of $L$. kefiri DMS 20587 as a source for $(R)$-specific ADH we obtained $(R)$-OHPTX, $(R)$-OHPPT and $(R)$-OHDBF with a biotransformation yield in the $98-100 \%$ range and ee values in the 95-98\% range. Accordingly, the procedure using LKADH should be employed in cases where the highest enantiopurity is necessary e.g. in pharmacokinetic/pharmacodynamic studies [23]. The other enzymes studied, TBADH and SAADH, displayed a high enantioselectivity, but unfortunately a low yield of bioconversion (5-10\%). DBF was not found in the substrate board of SAADH as no bioreduction process was observed to take place.

Tab. 2. Comparative data for the bioreduction of the drugs tested when using the whole cell methodology.

\begin{tabular}{cccc}
\hline Drugs & Biocatalyst & yield (\%) & $\begin{array}{l}\text { ee (\%) } \\
\text { (configuration) }\end{array}$ \\
\hline \multirow{2}{*}{ PTX } & L. kefiri & 100 & $98(R)[11]$ \\
& Yeast & 68 & $94(S)[29]$ \\
PPT & L. kefiri & 98 & $96(R)^{\mathrm{a}}$ \\
& Yeast & 67 & $78(S)[27]$ \\
DBF & L. kefiri & 98 & $95(R)[28]$ \\
& Yeast & 48 & $72(S)^{\mathrm{a}}$ \\
\hline
\end{tabular}

anpublished data.

From analysis of the data presented for bioreduction using the whole cell methodology with yeast (Table 2) $[27,29]$ it follows that it would be possible to obtain (S)-OHPTX, $(S)-O H P P T$ and $(S)$-OHDBF with biotransformation yields in the 48-68\% range and with ee values in the $72-94 \%$ range. In all the cases of bioreduction conducted using commercially-available ADHs it was necessary to make use of a very expensive cofactor: NADPH. This is a very interesting methodology, but from an economic point of view is expensive and less attractive.

\section{Experimental}

\section{Chemicals}

Some of the drugs used in this research were obtained as gifts from pharmaceutical companies (pentoxifylline from Polpharma, Poland; propentofylline from Intervet, Gemany), while the denbufylline comes from the University of Bonn, Germany. Alcohol dehydrogenase from $L$. kefir $(L K A D H)$, (S)-aromatic alcohol dehydrogenase from $T$. sp., alcohol dehydrogenase from T. brockii (TBADH) and NADPH were purchased from SigmaAldrich, USA. The HPLC grade dichloromethane, $n$-hexane, and 2-propanol were from Merck, Germany. All the other chemicals were of analytical reagent grade and were also obtained from Merck and Fluka, Germany. 


\section{Enzyme Assays}

LKADH assay: $10 \mathrm{mg}$ of NADPH, $660 \mu \mathrm{L}(8 \%)$ of 2-propanol, $0.02 \mathrm{mmol}$ of an appropriate ketone substrate and $20 \mathrm{mg}$ of $\angle K A D H(\sim 1 \mathrm{U} / \mathrm{mL})$ were added to a flask containing $8 \mathrm{~mL}$ of $50 \mathrm{mM}$ phosphate buffer ( $\mathrm{pH} 7$ ). In the case of DBF, which was insoluble in water, $200 \mu \mathrm{l}$ DMSO $(2.5 \%)$ was used as a cosolvent. The mixtures were then incubated for $36 \mathrm{~h}$ at $25^{\circ} \mathrm{C}$ and $180 \mathrm{rpm}$. Samples $(200 \mu \mathrm{L})$ were drawn at regular time intervals. The aqueous layer was extracted using dichloromethane, $3 \times 200 \mu \mathrm{L}$. The combined and dried $\left(\mathrm{Na}_{2} \mathrm{SO}_{4}\right)$ organic layers were evaporated to a residue which was then dissolved in 2-propanol and analyzed using HPLC.

TBADH assay: $10 \mathrm{mg}$ of NADPH, $500 \mu \mathrm{L}$ of 2-propanol, $0.02 \mathrm{mmol}$ of an appropriate ketone substrate and $20 \mathrm{mg}$ of TBADH $(\sim 4.5 \mathrm{U} / \mathrm{mL})$ were added to a flask containing 5 $\mathrm{mL}$ of $100 \mathrm{mM}$ phosphate buffer (pH 7.8). In the case of DBF, which was insoluble in water, $100 \mu \mathrm{L}$ DMSO (2\%) was used as a cosolvent. The mixtures were then incubated for $48 \mathrm{~h}$ at $40^{\circ} \mathrm{C}$ and $180 \mathrm{rpm}$. Samples $(200 \mu \mathrm{l})$ were drawn at regular time intervals. The aqueous layer was extracted using dichloromethane, $3 \times 200 \mu \mathrm{l}$. The combined and dried $\left(\mathrm{Na}_{2} \mathrm{SO}_{4}\right)$ organic layers were evaporated to a residue which was then dissolved in 2-propanol and analyzed using HPLC.

SAADH assay: $10 \mathrm{mg}$ of $\mathrm{NADPH}, 500 \mu \mathrm{L}$ of 2-propanol, $0.02 \mathrm{mmol}$ of an appropriate ketone substrate (PTX or PPT) and $\sim 1 \mathrm{U} / \mathrm{mL}$ of SAADH were added to a flask containing $5 \mathrm{~mL}$ of $100 \mathrm{mM}$ phosphate buffer $(\mathrm{pH} 7.8)$. The mixtures were then incubated for $48 \mathrm{~h}$ at $40{ }^{\circ} \mathrm{C}$ and $180 \mathrm{rpm}$. Samples $(200 \mu \mathrm{l})$ were drawn at regular time intervals. The aqueous layer was extracted using dichloromethane, $3 \times 200 \mu$ l. The combined and dried $\left(\mathrm{Na}_{2} \mathrm{SO}_{4}\right)$ organic layers were evaporated to a residue which was then dissolved in 2-propanol and analyzed using HPLC.

\section{HPLC analysis}

The yields of transformation and enantiomeric excess (ee) were determined using HPLC analysis on a Chiralpak AD Column. The high-performance liquid chromatograph (Dionex Corporation, USA) consisted of an isocratic solvent delivery system (Dionex HPLC Pump Series P580), an inlet equipped with a $20 \mu \mathrm{l}$ loop and a variable wavelength UV (Dionex UV/VIS detector UVD 170S/340S) set at $275 \mathrm{~nm}$. The analytical chiral column was a 250 $\mathrm{mm} \times 4.6 \mathrm{~mm}$ i.d. Daicel Chiralpak AD (Chemical Industries, France), protected with a 20 $\mathrm{mm} \times 4.6 \mathrm{~mm}$ LC-Si guard-column (Supelco, Inc., Bellfonte, PA, USA). The temperature was set at $25^{\circ} \mathrm{C}$. The mobile phase, consisting of n-hexane/ and 2-propanol (78:22 v/v, or 92:8 v/v), was vacuum-degassed before use and pumped at a flow rate of $1 \mathrm{ml} \mathrm{min}^{-1}$ for PTX and PPT and their bioreduction products, and $0.5 \mathrm{ml} \mathrm{min}^{-1}$ for DBF and its bioreduction product. Under these conditions the approximate retention times were: 7-(2-chloroethyl)-1,3-dimethylxanthine (internal standard): $11.80 \mathrm{~min}$; PTX: $22.45 \mathrm{~min}$; (R)-OHPTX: $25.45 \mathrm{~min}$; (S)-OHPTX: $28.87 \mathrm{~min}$; PPT: $16.12 \mathrm{~min}$; $(R)$-OHPPT: $14.25 \mathrm{~min}$; (S)-OHPPT: $18.20 \mathrm{~min}$; DBF: $35.98 \mathrm{~min}$, (R)-OHDBF: $25.45 \mathrm{~min}$; (S)-OHDBF: $28.87 \mathrm{~min}$. No interference was observed at the retention times in question.

\section{Acknowledgement}

We gratefully acknowledge the assistance of Professor C. E. Müller from University of Bonn in providing denbufylline. 


\section{Authors' Statement}

\section{Competing Interests}

The authors declare no conflict of interest.

\section{References}

[1] Fransson AB, Borén L, Pàmies $O$, Bäckvall JE.

Kinetic resolution and chemoenzymatic dynamic kinetic resolution of functionalized gamma-hydroxy amides.

J Org Chem. 2005; 70: 2582-2587.

doi:10.1021/jo0478252

[2] Patel RN, editor.

Kula M-R, Kragl U.

Dehydrogenases in the synthesis of chiral compounds.

In: Stereoselective Biocatalysis.

New York: Marcel Dekker, 2002: 839-866.

[3] Matsuyama A, Yamamoto H, Kobayashi Y.

Practical application of recombinant whole-cell biocatalysts for the manufacturing of pharmaceutical intermediates such as chiral alcohols.

Org Process Res Dev. 2000; 6: 558-561.

doi:10.1021/op025514s

[4] Drauz K, Waldmann $\mathrm{H}$, editors.

Nakamura K, Matsuda T.

Reduction of ketones.

In: Enzyme Catalysis in Organic Synthesis. Vol. 3.

Weinheim, Wiley-VCH, 2002: 991-1047.

[5] Hummel W, Abokitse K, Drauz K, Rollmann C, Gröger H.

Towards a large-scale asymmetric reduction process with isolated enzymes: expression of an (S)alcohol dehydrogenase in E. coli and studies on the synthetic potential of this biocatalyst.

Adv Synth Catal. 2003; 345: 153-159.

doi:10.1002/adsc.200390001

[6] Kroutil W, Mang H, Edegger K, Faber K.

Recent advances in the biocatalytic reduction of ketones and oxidation of sec-alcohols.

Curr Opin Chem Biol. 2004; 8: 120-126.

doi:10.1016/j.cbpa.2004.02.005

[7] Ryzewski CN, Pietruszko R.

Horse liver alcohol-dehydrogenase SS-purification and characterization of homogeneous isoenzyme. Arch Biochem Biophys. 1977; 183: 73-82.

doi:10.1016/0003-9861(77)90420-9

[8] Keinann E, Hafeli EK, Seth KK, Lamed R.

Thermostable Enzymes in Organic Synthesis. 2. Asymmetric reduction of ketones with alcohol dehydrogenase from Thermoanaerobium brockii.

J Am Chem Soc. 1986; 108: 162-169.

doi:10.1021/ja00261a026

[9] Peretz M, Bogin O, Tel-Or S, Cohen A, Li G, Chen J-S, Burstein Y.

Molecular cloning, nucleotide sequencing, expression of genes encoding alcohol dehydrogenases from the thermophile Thermoanaerobacter brockii and the mesophile Clostridium beijerinckii.

Anaerobe. 1997; 3: 259-270.

doi:10.1006/anae.1997.0083 
[10] Abokitse K, Hummel W.

Cloning, sequence analysis, and heterologus expression of the gene encoding a (S)-specific alcohol dehydrogenase from Rhodococcus erythropolis DMS 4329.

Appl Microbiol Biotechnol. 2003; 62: 380-386.

doi:10.1007/s00253-003-1310-y

[11] Pękala E, Godawska-Matysik A, Żelaszczyk D.

Enantioselective reduction of pentoxifylline to lisofylline using whole-cell Lactobacillus kefiri biotransformation.

Biotechnol J. 2007; 2: 492-496.

doi:10.1002/biot.200600236

[12] Hummel W.

New alcohol dehydrogenases for the synthesis of chiral compounds.

Adv Biochem Eng/Biotechnol. 1997; 58: 146-184.

doi:10.1007/BFb0103299

[13] Weckebecker A, Hummel W.

Cloning, expression, and characterization of $(R)$-specific alcohol dehydrogenase from Lactobacillus kefir.

Biocatal Biotransform. 2006; 24: 380-389.

doi:10.1080/10242420600893827

[14] Prelog V.

Specification of the stereospecificity of some oxidoreductases by diamond lattice sections.

Pure Appl Chem. 1964; 9: 119-130.

doi:10.1351/pac196409010119

[15] Nakamura K, Yamanaka R, Matsuda R, Harada T

Recent development in asymmetric reduction of ketones with biocatalysts.

Tetrahedron Asymmetry 2003; 14: 2659-2681.

doi:10.1016/S0957-4166(03)00526-3

[16] Bradshaw CW, Hummel W, Wong C-H.

Lactobacillus kefir alcohol dehydrogenase: a useful catalyst for synthesis.

J Org Chem. 1992; 57: 1532-1536.

doi:10.1021/jo00031a037

[17] Deeks NJ, Graeme T, Smith NA, Thawley U, Thawley AR.

Specific high-performance liquid chromatography method for the quantitative determination of denbufylline and its metabolites in plasma.

Analytical Proceedings. 1990; 27: 179-180.

doi:10.1039/AP9902700176

[18] Reim HG, Kurowski H, Bosch K, Brett MA, Ellrich E, Hotzel L, Holtz B, Hust R.

Pharmacokinetics of denbufylline in healthy elderly subjects.

Eur J Metab Pharmacokinet. 1991; 3: 274-276.

PMid:1820891

[19] Mancinelli S, Pace S, Marzo A, Martelli EA.

Determination of pentoxifylline and its metabolites in human plasma by high-performance liquid chromatography with solid phase extraction.

J Chromatogr. 1992; 575: 101-107.

doi:10.1016/0378-4347(92)80509-O

[20] Lilibridge JA, Kalhorn TF, Slattery JT.

Metabolism of lisofylline and pentoxifylline in human liver microsomes and cytosol.

Drug Metab Dispos. 1992; 24: 1174-1179.

PMid:8937849 
[21] Parkinson EE, Mukherjee K, Geiger JD.

[3H] adenosine transport in DDT1 MF-2 smooth muscle cells, inhibition by metabolites of propentofylline.

Eur J Pharmacol. 1996; 308: 97-102.

doi:10.1016/0014-2999(96)00259-2

[22] Kuroda N, Hamachi, Y, Aoki N, Wada M, Tanigawa M, Nakashima K.

Simple and rapid high-performance liquid chromatography analysis of propentofylline and its main metabolites in serum using a direct injection technique.

Biomed Chromatogr. 1999; 13: 340-343.

doi:10.1002/(SICI)1099-0801(199908)13:5<340::AID-BMC883>3.0.CO;2-V

[23] Wyska E, Pękala E, Szymura-Oleksiak J.

Intraconversion and tissue distribution of pentoxifylline and lisofylline in mice.

Chirality. 2006; 18: 644-651.

doi:10.1002/chir.20299

[24] Wong JS, Ara G, Keyes SR, Herbst R, Coleman CN, Teicher BA.

Lisofylline as a modifier of radiation therapy.

Oncol Res. 1996; 8(12): 513-517.

PMid:9160355

[25] Cui P, Macdonald TL, Chen M, Nadler J.

Synthesis and biological evaluation of lisofylline (LSF) analogs as a potential treatment for Type 1 diabetes.

Bioorg Med Chem Lett. 2006; 16: 3401-3405.

doi:10.1016/j.bmcl.2006.04.036

[26] Parkinson EE, Mukherjee K, Geiger JD.

[3H] adenosine transport in DDT1 MF-2 smooth muscle cells, inhibition by metabolites of propentofylline.

Eur J Pharmacol. 1996; 308(1): 97-102.

doi:10.1016/0014-2999(96)00259-2

[27] Pękala E, Latacz G, Wójcik T.

Enantioselective bioreduction of propentofylline using yeast in water and in organic solvents.

Biotechnologia. 2007; 2: 174-180.

[28] Pękala E, Burbiel JC, Müller CM.

Preparation of enantiopure (R)-hydroxy metabolite of denbufylline using immobilized Lactobacillus kefiri DMS 20587 as a catalyst.

Chirality. 2009; in press.

doi:10.1002/chir.20665

[29] Pękala E, Wójcik T.

Enantioselective biotransformation of pentoxifylline into lisofylline using wine yeast biocatalysis.

Acta Pol Pharm. 2007; 64: 109-113.

PMid:17665859 